\title{
Jogos tradicionais no Estado do Rio Grande do Sul: manifestação pulsante e silenciada
}

\author{
Elizara Carolina Marin ${ }^{*}$ \\ João Francisco Magno Ribas** \\ Pierre Parlebas ${ }^{* * *}$ \\ Fernanda Stein ${ }^{* * * *}$ \\ Alini de Vargas Crestani*****
}

\begin{abstract}
Resumo: Este artigo resulta de pesquisa descritiva que objetivou situar os jogos tradicionais no contexto histórico e sociocultural do RS, realizada em municípios com expressivos traços das culturas alemã e italiana. Para a coleta dos dados, utilizamos formulários e entrevistas semi-estruturadas. Podemos dizer que há tanto uma diversidade de jogos sendo vivenciados, sendo associações e bares os locais centrais dessa vivência, quanto há jogos extintos ou em vias de extinção apresentados como espetáculo. Os jogos tradicionais no RS fazem reviver o patrimônio de um passado em acelerado processo de mudanças, mas que para a geração atual, mesmo com mutações sociais, eles representam um indiscutível prolongamento histórico.
\end{abstract}

Palavras-chave: Cultura alemã. Cultura italiana. Jogos tradicionais. Patrimônio histórico.

\footnotetext{
"Universidade Federal de Santa Maria (UFSM). Santa Maria, RS, Brasil. E-mail: elizaracarol@yahoo.com.br

"UFSM. Santa Maria, RS, Brasil. E-mail: ribasjfm@hotmail.com

"'Université Paris-Descartes; Faculté des Sciences Humaines et Sociales, Sorbonne. França. E-mail: pparlebas@free.fr

*.*UfSM. Santa Maria, RS, Brasil. E-mail: fefestein@yahoo.com.br

.....UFSM. Santa Maria, RS, Brasil. E-mail: alinicrestani@bol.com.br
} 


\section{INTRODUÇão}

Os ventos da mundialização provocam mudanças substanciais no contexto dos jogos tradicionais. As mudanças tecnológicas e culturais pelo qual passa o conjunto das sociedades tendem a provocar o abandono dos costumes antigos e a substituir práticas do passado por novos comportamentos.

Com a hegemonia da empresa (MATTELART, 1997), a paisagem humana tende a ficar cada vez mais artificial e povoada "[...] por sistemas de ações igualmente imbuídos de artificialidade" (SANTOS, 2004, p.63), permeados por mecanismos técnicos produtores de sensações, visando resultados, produtos e objetos. Essa hegemonia impõe limite às opções humanas, quer pelo acirramento das contradições sociais, quer pela necessária mediação dos mecanismos organizados pela esfera da produção nos diferentes âmbitos da vida humana.

No domínio das manifestações lúdicas, a mudança é espetacular: os jogos das sociedades tradicionais são substituídos pelos modernos em proveito de jogos atrelados a um processo de alta lucratividade, como os jogos eletrônicos. Nesta direção, de modo similar, entram em cena os chamados "esportes" institucionalizados que obtiveram grande impulso no decorrer do século XX. Os jogos tradicionais não somente estão cada vez mais preteridos como também passaram a serem qualificados de jogos "inferiores" ou do passado.

Empregamos o termo jogo às atividades submetidas a um sistema de regras. Este sistema define a estrutura e o modo de funcionamento da atividade, ou seja, sua lógica interna. Por jogos tradicionais, entendemos aqueles pertencentes à cultura historicizada de um povo ou etnia, desenvolvidos e preservados pelo processo de transmissão oral e que são praticados por uma comunidade durante um determinado período. Portanto, combinam representatividade e temporalidade. (LAVEGA BURGUÉS, 2000) 
Nessa esteira, Parlebas (2001) caracteriza o "jogo tradicional" a partir de alguns elementos centrais: [a] aparece ligado à tradição de uma cultura, mas sempre relacionado ao tempo livre, religião, colheitas, estação do ano, espaços; [b] é regido por um corpo de regras flexíveis que admitem muitas variantes, em função dos interesses dos participantes; [c] mantém-se à margem dos processos sócio-econômicos - mesmo o jogo sofrendo influência desses processos, não depende diretamente deles para acontecer e se perpetuar; e, [d] suas práticas independem de instâncias oficiais.

O jogo tradicional, com seu sistema de regras, é construído pelos grupos sociais que o praticam em consonância com as regiões em que se desenvolvem, pois a geografia e os costumes influenciam na sua organização. Os jogos tradicionais dependem diretamente das condições espaciais do seu estorno e põe-se em conformidade com os hábitos de vida dos que os desenvolvem e os recriam.

Nesse sentido, cada jogo tradicional foi desenvolvido ao longo de uma história e de uma cultura. O Rio Grande do Sul oferece um caso particular, pois foi profundamente agitado pela colonização vinda da Europa e da África. Cada colonização que se implantou no Brasil tentou construir modos próprios de viver, de comunicar e de pensar o mundo. Os jogos viajaram clandestinamente nos navios dos missionários, dos mercadores, dos soldados e à revelia das políticas migratórias. Assim foi provocado um confronto entre os jogos dos autóctones e os jogos dos imigrantes. Um fenômeno típico da aculturação nunca é unilateral: o colonizador impõe sua prática, mas esta é, habitualmente, em maior ou menor grau, modificada e adaptada pelos autóctones (BOSI, 1992).

A aculturação frequentemente produz comportamentos, músicas e jogos que não conservam integralmente seus traços originais, e assim tornam-se mestiçados. Ritualizações são reproduzidas, mas com modificações que se mantenham em harmonia com a região de acolhida. É assim que se enriquece um patrimônio. Sim, pois não existe cultura "pura", mas culturas que se reorganizam em função 
das influências vindas de outras partes. No seio dessas mestiçagens mais ou menos pronunciadas, uma região propõe as orientações de predileção que ilustram as grandes tendências da cultura de pertencimento.

É nessa direção que o artigo se enuncia, ou seja, objetiva situar os jogos tradicionais dos grupos sociais alemães e italianos e as relações existentes com o contexto histórico e sociocultural no Rio Grande do Sul.

\section{MÉtodos}

A pesquisa, caracterizada como descritiva (CERVO; BERVIAN, 1983), dedicou-se a realizar levantamento e descrição detalhada dos significados e características situacionais dos Jogos Tradicionais, relativo à lógica interna e lógica externa dessas em municípios escolhidos por apresentarem expressivos traços da cultura alemã (Agudo - Região Central; Nova Petrópolis - Região das Hortências; e Santa Cruz do Sul - Região do Vale do Rio Pardo) e italiana (Bento Gonçalves - serra gaúcha; e São João do Polêsine Região Central) ${ }^{1}$, e também por serem municípios já abarcados por estudos anteriores, o que viabilizou o contato com os espaços e sujeitos da pesquisa.

Como fonte de informações, utilizamos as páginas eletrônicas que contemplam dados sobre o contexto econômico, social e cultural dos municípios pesquisados; a mídia impressa; os documentos oficiais das Secretarias de Esporte e Turismo dos Municípios; os sujeitos

\footnotetext{
${ }^{1}$ Agudo é um município que contempla 16.716 de habitantes. Sua economia está centrada na agropecuária, indústria, comércio e prestação de serviços. Nova Petrópolis estima uma população de 19.025 habitantes e sua economia está centrada no turismo, em produtos industriais, como calçados, móveis, laticínios e malhas, além da agricultura e da pecuária. Santa Cruz do Sul tem sua economia centrada na produção do fumo, no comércio e serviços, e estima uma população de 117.214 habitantes. Bento Gonçalves estima uma população de 104.470 habitantes, sendo que $90 \%$ vive na zona urbana. A base de sustentação econômica está relacionada com os setores de móveis, transporte, fruticultura e vinícola. São João do Polêsine estima uma população de 2.633 habitantes, sendo que $50 \%$ vive no meio rural. A base de sustentação econômica está relacionada com a agropecuária de pequenas e médias propriedades. FONTE: IBGE, 2010.
} 
sociais envolvidos na organização e desenvolvimento dos jogos tradicionais; e os próprios espaços onde os jogos ocorrem. Como instrumentos de coleta das informações, foram adotados roteiros para buscas nas páginas eletrônicas, nos documentos oficiais e na mídia impressa, bem como entrevistas semi-estruturadas.

Para consecução do reconhecimento do contexto do jogo nos municípios pesquisados (lógica externa) e compreensão do funcionamento do jogo (lógica interna), foram feitas visitas a museus e prefeituras, realizadas entrevistas com jogadores, organizadores dos jogos e historiadores, e percorridos espaços urbanos e rurais para observar e registrar os jogos e eventos no momento em que eles ocorriam. Seguimos os passos propostos por Richardson e Col.(2010) para métodos de pesquisas críticas em ciência sociais: seleção e familiarização com os distintos contextos da pesquisa; definição das relações com os entrevistados; coleta das informações propriamente dita; análise das informações com base na lógica dialética; e elaboração do relatório final.

\section{Discussão}

\subsection{Grupo Social Alemão}

No início do século XIX, em virtude da política econômica, dominada pelo modelo capitalista industrial que gerou excedentes populacionais, milhões de europeus deixaram para trás seu país de origem; dentre estes, principalmente, os camponeses e os artesãos. A colonização no sul do Brasil foi introduzida pelo governo imperial fundamentalmente com objetivos econômicos, dos quais se podem destacar: ocupar grandes extensões de terras "vazias" desprezadas para pecuária; introduzir a pequena propriedade voltada ao mercado interno; e, o mais importante, substituir a mão de obra escrava pelo trabalho livre, já que tomava forças o movimento abolicionista. Os vales dos grandes rios do Rio Grande do Sul (RS) foram ocupados principalmente pelos imigrantes alemães. 
O processo da colonização alemã no RS teve início, a partir de 1825, com a criação da Colônia de São Leopoldo e se estendeu por longos anos com a chegada de novos imigrantes e a criação de novas colônias (SCHUCH, 2008). Houve a criação de aproximadamente 20 colônias alemãs que se constituíram mais tarde em municípios.

No período de colonização, o envolvimento tanto com a política nacional quanto com a estadual era restrito. Ocorreu o que se pode denominar de uma política de abandono em relação à assistência básica: abertura de estradas, construção de escolas e auxílio à saúde. Diversos autores (PAZ, 1998; SCHUCH, 2008) relatam que este foi um período de muito sofrimento, fome e doenças. Contudo, havia entre eles um sentimento de associativismo, ou seja, uma tendência a trabalhar cooperativamente para resolver seus problemas (abrir estradas, construir escolas, igrejas, cemitérios, dentre outros). Rockenbach e Flores (2004, p.47) destacam o associativismo como uma "tendência do imigrante alemão" de se organizar e constituir um espaço para resolução coletiva de dificuldades enfrentadas pela colônia, principalmente de infraestrutura. Além disso, esta característica das colônias alemãs ajudou na construção em "bases sólidas" os valores étnicos e culturais trazidos pelos imigrantes.

No processo de estruturação e suprimento das necessidades básicas da população, em face do não atendimento destas pelo Estado, as colônias passaram a ter como um dos pontos centrais de sua organização social, as Sociedades.

As Sociedades (associações, sem fins lucrativos, ligadas a uma comunidade) se constituíam como ente espaciotemporal em torno das quais a vida social era organizada; as famílias integravam-se e cultivavam costumes, preservavam a cultura e impulsionavam não apenas o fortalecimento da colônia como também as manifestações culturais que caracterizavam o grupo social.

Em Nova Petrópolis, formada por imigrantes de origem diversa, fatores como distância e isolamento político em relação aos maiores centros favoreceram uma organização de vida comunitária, com a 
reconstrução da cultura nos moldes do país de origem, onde igreja, escola e associações tiveram papel central. Este fator favoreceu também que a população conservasse suas tradições, constatadas até os dias de hoje em festas como o Kerb², Bailes do Tiro Rei, torneios de Bolão, Festival do Folclore, grupos de canto e de danças folclóricas. Segundo o historiador Renato Seibt:

Inicialmente as Sociedades estavam agregadas aos salões das vendas. Basicamente as primeiras e mais importantes foram as Sociedades de fundo cultural, no caso, as sociedades de canto. Não quer dizer que eles só cantavam, juntamente com o canto praticavam jogos no qual o bolão era um dos preferidos. Quase todos os imigrantes tocavam instrumentos, em especial de sopro e, nas horas de folga, se reuniam para cantar e tocar. Também surgiram as Sociedades de Atiradores, não eram Sociedades de Caça como muita gente pensa, mas de atiradores esportistas (Entrevista - Renato Seibt, 75 anos, Nova Petrópolis, 18-09-2010).

Como observa Schuch (2008), no estudo que realiza sobre a colonização de Santa Cruz do Sul, as Sociedades exerceram papel decisivo de integração, defesa, preservação da cultura e constituição de novas famílias. Segundo a pesquisa realizada por este autor, no âmbito da imigração alemã, em 1860 começaram a serem criadas as primeiras Sociedades, tendo como modalidades pioneiras o Tiro Rei e o Bolão. A partir daí, as Sociedades se disseminaram em praticamente todas as comunidades. Este autor catalogou 109 Sociedades no município de Santa Cruz em que se destacam: Sociedade de Atiradores, de Bolão, de Lanceiros e de Damas nestas os participantes, em sua maioria mulheres, envolvem-se, dentre outras atividades, nos jogos de Bolão de Mesa, Bolão de Bola Presa e Loto.

\footnotetext{
${ }^{2}$ Segundo Paz (1998, p.70) "esta expressão se constitui na abreviatura da palavra Kircheweifest (festa da inauguração da igreja) e marca anualmente a data inaugural da igreja na comunidade". Trata-se de uma festa que reúne famílias da própria comunidade e das cidades vizinhas em torno da comida, bebida, música e dança típica alemã.
} 
O Centro Cultural 25 de Julho, por exemplo, tem na sua agenda, desde longa data, a última sexta-feira do mês destinada à vivência de diferentes jogos tradicionais germânicos, desde canto, música, incluindo-se aí a comida alemã.

Com o evento das duas Grandes Guerras (1914-1918; 19391945) as Sociedades foram duramente atingidas: a língua alemã foi proibida, documentos destruídos e muitas atividades suspensas, sendo as mais atingidas as de Tiro, Lanceiros e Cavalarianos.

Embora muitos dos traços culturais presentes nas Sociedades tenham sido abalados, a partir de 1980 inicia-se um amplo movimento de diferentes segmentos sociais visando a recuperação tanto da autoestima quanto da identidade cultural, via arquitetura, eventos, culinária, canto, idioma e resgate de jogos e que erige as cidades pesquisadas em centros turísticos (PAZ, 1998). Neste movimento histórico, parte dessa tradição se manteve (entretanto não mais nas mesmas feições) e até os dias de hoje, realizam-se, por exemplo, torneios e concursos de Tiro Rei.

As Sociedades de Tiro ao Alvo pertencem a uma tradição já existente na Idade Média e que se espalhou por toda a Europa (BENEVENUTO; SEIBT \& SEIBT, 2006). Os atiradores treinavam suas habilidades para defenderem os feudos aos quais pertenciam. Incorporando as antigas sociedades de tiro da Europa Medieval, os alemães instalados no sul do Brasil, sem apoio imperial, no que tange à proteção policial, formaram as Schützenvereine (Associações de Proteção), responsáveis por defender a colônia em situações de invasão e saques de mantimentos, de animais domésticos e de armas.

Em Nova Petrópolis e Santa Cruz do Sul foram encontradas Sociedades de Tiro. Hoje o Tiro ao Alvo é desenvolvido em festividades e campeonatos e, em Nova Petrópolis, faz parte da tradicional festa alemã "Tiro Rei", em que a partir da disputa de tiro, todos os anos um "rei" e uma "rainha" da comunidade são consagrados.

Outra Sociedade comum entre os homens eram as Sociedades de Cavalaria. Seus membros eram denominados Ulanos (termo que 
designa soldados da cavalaria ligeira, armados com lança). Essas sociedades cultivavam o Jogo dos Lanceiros: um lanceiro sobre o cavalo tem como objetivo acertar um alvo de couro com sua lança. O jogo foi adaptado e atualmente denominado de Rutschbahn (trem deslizador), em que, no lugar de um cavalo, o jogador se posiciona com sua lança numa cadeira de madeira, que desliza por meio de um sistema de roldanas, dificultando a proeza de acertar o alvo. Em entrevista com Luiz Carlos Kaufmann, membro do Centro Cultural 25 de Julho, identificamos no que consistia o Jogo do Lanceiro e como ele foi modificado para o Rutschbahn:

[...] isso tudo era praticado com cavalos. O pessoal localizava um corinho a uma certa distância e montados no cavalo, correndo, com uma lança em baixo do braço, tentava acertar o corinho cheio de furos (...) cada jogador tem três chances para espetar o corinho. Então quem fez mais pontuação será declarado o campeão. Mas hoje em dia como a gente não pode usar animais no meio da festa, então fabricamos uma cadeira num aclive presa por um cabo de aço. Então tudo é manual. A gente puxa essa cadeira pra cima, a pessoa sobe em uma escada e senta na cadeira e a gente larga. É tipo um cavalo de madeira (Entrevista - Luiz Carlos Kaufmann, 49 anos, Santa Cruz do Sul, 11-09-2010).

Entre as mulheres, as Damenvereine (Associações de Damas) perduram, mas não na mesma quantidade de décadas atrás. Além de grupos de canto e de dança, em Santa Cruz do Sul, elas se reúnem uma vez por semana para jogar Bolão de Mesa. Na região rural do município encontram-se grupos de mulheres, que se reúnem para jogar Loto - comumente chamada de Víspora, um jogo similar ao Bingo.

O contexto histórico dos imigrantes que se estabeleceram e formaram suas colônias, que constituíram a Sociedade e a forma de organização da vida dentro da colônia, denota que os grupos se formaram a fim de compartilhar propósitos, costumes, gostos e preocupações, e que tiveram papel fundamental na composição da identidade social e cultural da população, o que ainda hoje assume 
um papel central em muitas comunidades. A historiadora Maria Luiza Rauber Schuster, conta que:

[...] as Sociedade de Damas perduram até hoje, e para os homens, a Sociedade de Cavalaria e Sociedade de Tiro ao Alvo. Na verdade eles se reuniam pra congratular, pra trocar ideias, pra preservar a língua. Nesses momentos eles cantavam, eles conversavam sobre o trabalho que eles estavam realizando na lavoura, muitas vezes combinavam mutirões da semana e ao mesmo tempo eles praticavam o lazer. (Entrevista - Maria Luiza Rauber Schuster, 48 anos, Santa Cruz do Sul, 12-09-2010).

Considerando os três municípios pesquisados, identificamos vinte e sete (27) jogos tradicionais diferentes ${ }^{3}$. Destes, três (3) estão presentes nos três municípios (Bolão, Bolão de Mesa e a prova de Serrar a Tora); e cinco (5) são jogados em pelo menos dois deles (Schafkopf [cabeça de ovelha - jogo de cartas], Tiro ao Alvo, Bolão de Bola Presa, Corrida do Tamanco e Loto).

Em Santa Cruz do Sul, doze (12) jogos são desenvolvidos por Sociedades ou Clubes do município (Bolão, Bolão de Bola Presa, Bolão de Mesa, Loto, Corona, Mini-stock, Eisstocksport [jogo em que os participantes fazem deslizar discos para atingir um alvo], Sprangelspiel [jogo em que os participantes fazem deslizar discos para atingir placas de metal no final da pista], Tiro ao Alvo, Corrida do Tamanco, Serrar a Tora, Argolinha) e alguns durante a Oktberfest (festividade anual da cerveja ocorrida em outubro).

Em Agudo diagnosticamos o cultivo de cinco (5) jogos tradicionais (Bolão, Bolão de Mesa, Loto, Schafkopf e Canastra). Identificamos também o desenvolvimento das Olimpíadas Rurais que contemplam provas, tais como Serrar a Tora, Cabo de Guerra e Estilingue.

\footnotetext{
${ }^{3} \mathrm{~A}$ descrição do funcionamento do jogo com suas regras e objetivos, ou seja, a lógica interna, está disponível no Mapa dos Jogos Tradicionais no RS, localizado no endereço: < www.ufsm.br/ gpelf >
} 
O Bolão, que assume juntamente com o Eisstocksport e o Tiro ao Alvo características de esporte institucionalizado, é o jogo com maior expressividade e difundido nos três municípios pesquisados, concentrando um grande número de jogadores. O jogo de Bolão é orientado pela Federação de Bolão do Rio Grande do Sul, que regulamenta as regras do jogo, controlam o espaço e suas medidas (extensão) e os materiais (peso e dimensões). Encontramos, nos diferentes espaços sociais que compõem os municípios investigados, tanto o jogo sendo jogado utilizando-se das regras institucionalizadas, quanto adaptado ao contexto local, cultural e às condições materiais.

Em Nova Petrópolis encontramos vinte (20) jogos, treze (13) deles constituem parte das festividades do Festival Internacional do Folclore e dos Jogos Germânicos de Pinhal Alto (Bolão, Bolão de Bola Presa, Bolão de Mesa, Tiro Rei, Canastra, Schafkopf; Roda pião, Cabo de Força, Arremesso de Chopp, Chopp em metro, Corrida do Tamanco, Corrida do Tronco, Serrar Tronco, Pregar o Prego, Bolão de Corda, Ensacar Milho, Boliche de Chucrutes, Pau de Sebo, Pegar o Porco, Pegar a Galinha). As manifestações desenvolvidas nessas festividades resgatam e ressignificam os costumes dos imigrantes que colonizaram a região. Provas como Ensacar Milho, Serrar a Tora, Corrida do Tamanco, Pegar o Porco, entre outras, expressam em forma de jogo e diversão o cotidiano até hoje vivido pelos descendentes de alemães que se mantiveram na região. Nestas manifestações, o jogo expressa o trabalho e o trabalho é reconfigurado em jogo.

A gente procura jogos que tenham a ver com o cotidiano das pessoas, lá na colônia. Lá no interior você vai ver as pessoas ensacando milho, tocando os porcos pra dentro do chiqueiro, cortando lenha com serrote. Então na verdade, as localidades disputam, de modo saudável obviamente, mas representando o nosso cotidiano, dos dias de hoje. (Entrevista - Cláudio José Weber, 44 anos, Nova Petrópolis, 18-09-2010).

Como explicita Bosi (1987), a cultura está vinculada ao processo de trabalho, da transmissão do conhecimento aplicado ao 
trabalho e de sua tradição, que passa de geração a geração. No entendimento de cultura como processo, a transmissão e a aprendizagem assumem papel fundamental. No contexto do jogo tradicional, a transmissão e o aprendizado do Bolão (anterior às pistas automáticas) são singulares: o aprendizado se dava, conforme depoimentos, pela observação de ver o pai jogando e assumindo a tarefa de levantar os pinos em cada lançamento. Lauro Reinaldo Reetz, jogador de Bolão, narra tal aprendizado ao contar como ajudava o seu pai a levantar os pinos (bonecos) durante o jogo:

Quando eu era criança e não tinha o automático era eu quem levantava. Ganhava a janta e um refrigerante no baile daquela festa (...) com oito, nove anos. $\mathrm{O}$ pai ia lá jogar. Então tinha que ter a disponibilidade de no mínimo quatro jovens, seja guri, seja guria. Primeiro começamos juntando boneco. E daí já tinha direito de ir treinando (Entrevista - Lauro Reinaldo Reetz, 69 anos, Agudo, 02-06-2010).

Burgos et. al. (2005), em seu estudo, relata que grande parte dos praticantes dos jogos tradicionais reside na zona rural e aponta a hipótese de que estas manifestações são mais cultivadas pelos descendentes que moram no interior dos municípios por ser uma das poucas possibilidades de lazer disponíveis dessa população.

Entretanto, durante nossa pesquisa, identificamos tais manifestações culturais no contexto urbano e rural, como vida pulsante, como reprodução de valores socioculturais e de vivência do tempo local, coexistindo com o processo de mundialização da cultura, para além, portanto, da interpretação de única possibilidade de diversão.

No que se refere às instituições organizadoras, a pesquisa identificou que as prefeituras municipais e os órgãos públicos demonstram pouco apoio às manifestações de jogos tradicionais. Em geral, os jogos são mantidos pelas Sociedades e pelos Clubes privados que, a partir de taxas ou mensalidades (por vezes simbólicas), pagas por seus membros, conservam os locais e materiais destinados aos jogos, além do cultivo de tais manifestações no cotidiano familiar, como, por exemplo, os jogos de carta: Canastra e Schafkopf. 


\subsection{Grupo Social Italiano}

A presença de descentes italianos no Rio Grande do Sul está relacionada diretamente ao processo de colonização movido pelas políticas do governo Imperial do Brasil do século XIX e ao processo de expansão do capitalismo a partir dos países europeus, neste caso, na Itália ${ }^{4}$. A crise social, política e econômica pela qual passava a Itália e a consequente miséria que assolava esse país tiveram como efeito, entre outros, a migração compulsória de um expressivo contingente populacional e, neste particular, majoritariamente trabalhadores rurais, com o claro objetivo de reduzir tensões sociais.

No período de 1875 a 1914 , em torno de $75 \%$ da imigração brasileira era proveniente da Itália. Em 1888, ano crítico da economia italiana e ano da abolição da escravatura no Brasil, o número de imigrantes naturais da Itália era de 104.353 pessoas. Em 25 anos, cerca de um milhão de italianos se estabeleceu no Brasil.

No Rio Grande do $\mathrm{Sul}^{5}$, a colonização italiana teve início em 1875. As primeiras Colônias Italianas fundadas no Rio Grande do Sul foram: Conde D'Eu, atual Garibaldi; Dona Isabel, atual Bento Gonçalves; Fundos de Dona Palmeira, atual Caxias do Sul, que se localizam na microrregião da serra, a nordeste do estado. Em 1876, no centro do estado, foi fundado o Quarto Núcleo de colonização como o nome de Núcleo Colonial de Santa Maria da Boca do Monte, atual Silveira Martins, região onde se situa São João do Polêsine.

Considerando os dois municípios pesquisados, identificamos dez (10) jogos diferentes: Bocha, Bocha 48, Bolão, Mora, Quatrilho, 3sete, Bisca, Canastrinha, Menos Copa, e Cinquilho. Destes jogos, cinco (5) deles estão presentes nos dois municípios: Bocha, Bocha 48, 3sete, Mora, Cinquilho. Em São João do Polêsine e municípios fronteiriços, identificamos a realização das Olimpíadas Rurais, que

\footnotetext{
${ }^{4}$ Como assinala IANNI (1979, p.12), "o fenômeno migratório havido do século XIX ao século XX está ligado diretamente à expansão do capitalismo europeu e às transformações das estruturas políticas, econômicas, sociais, vigentes na Europa e no Brasil, herdados de um período anterior que era, na Europa, feudalismo e, no Brasil, escravatura".

${ }^{5}$ Vários autores tratam da questão da imigração italiana no Rio Grande do Sul, dentre eles destacam-se GIRON (1992), BONI (1982) e COSTA (1986).
} 
contemplam diferentes provas ligadas ao trabalho rural: Arremesso de Espiga, Cabo de Guerra, Corrida da Carriola, Corrida de Carrinho com revezamento, Corrida do Saco, Corrida de 100 metros, Debulhar Milho e Corrida do Ovo.

No interior (distritos) de ambos os municípios pesquisados, o jogo (assim como as festas) aparece como um dos vínculos de sustentação da vida comunitária e se realiza fundamentalmente por meio dos encontros nas Sociedades, no sábado à noite e no domingo à tarde. Nos centros urbanos, a exemplo de Bento Gonçalves, os encontros para os jogos dos grupos de adultos ocorrem em Bares e Clubes durante toda a semana.

A Bocha é o jogo mais cultivado e assume características de jogo institucionalizado, orientado e regulamentado por uma Federação Esportiva (todavia em algumas Sociedades encontra-se em fase de regressão). Pode-se dizer que em cada comunidade há uma Sociedade, e nesta, uma cancha de bocha. Segundo relatos, muitas famílias construíram canchas de bocha em suas residências com finalidade de diversão e de agregação vicindária.

Nas Sociedades e Clubes onde a prática está vigente, geralmente é usado o regulamento da Associação Riograndense de Bocha. No caso de Bento Gonçalves, há a Liga Bentogonçalvense de Bocha Pontobol, responsável por organizar o calendário de campeonatos local e regional. Em torno de quarenta (40) Clubes ou Sociedades participam dos campeonatos com jogadores de diferentes idades e profissões.

Outro jogo que, resultado das trocas culturais com os descendentes de alemães, foi resgatado recentemente é o Bolão. Atualmente, ele é orientado por uma federação desportiva. Há calendário interno das Sociedades e Clubes tanto para os treinos quanto para os torneios e seguem as regras da Federação de Bolão do Rio Grande do Sul. Vale realçar, assim como consideramos anteriormente, que esses jogos (principalmente quando excedem os campeonatos) são jogados segundo o contexto local, cultural e às condições materiais. 
Constatamos uma forte presença dos jogos de carta no universo lúdico deste grupo social: em Bento Gonçalves, principalmente, o Quatrilho, a Bisca e o Menos Copa; e em São João do Polêsine, o Cinquilho (em processo de extinção) e o 3sete.

No município de Bento Gonçalves, os jogos de cartas se desenvolvem em Bares, que passam a serem reconhecidos pela comunidade em geral por esta especificidade e por reunir uma diversidade de jogadores, na sua maioria, homens acima de 30 anos. Há Bares que reúnem aproximadamente 50 pessoas, entre jogadores e observadores, todos os dias da semana, após 17 horas, e outros, aos domingos, nos turnos da manhã e da tarde. Conforme narra Cândido Valdulga, "o Menos Copa jogamos só no domingo de manhã (...). Durante a semana jogamos 3Sete, Bisca e Quatrilho". (Entrevista - Cândido Valdulga, 78 anos, Bento Gonçalves, 26-06-2010).

No jogo de cartas, fica claro que os ânimos se renovam a cada rodada (distribuição de novas cartas) com a criação de novas combinações. A imprevisibilidade das cartas e do companheiro (em alguns jogos) gera emoções diversas, tanto há silêncios quanto vozes exaltadas, reclamações, relatos, discussões, risos em torno do jogo e ao que excede o jogo - o cotidiano -, quase sempre no idioma italiano. Ali, se estabelecem formas particulares de comunicação, inconcebíveis em outras situações da vida ordinária.

O Quatrilho encontra-se em fase de progressão, em virtude da fundação da Associação Brasileira dos Amigos de Quatrilho (ABAQ), desde 2006, por aficionados desse jogo. A Associação passou a organizar campeonatos nacionais com a participação de jogadores de vários estados brasileiros, especialmente do Sul e Sudeste.

A presença das mulheres no interior das Sociedades e Clubes não é de longa data, principalmente para jogar, nem mesmo segue uma regularidade. Aquelas (vítimas, às vezes, de comentários pejorativos de alguns e admiradas por outros) que romperam as barreiras morais e culturais que as impediam de se sentarem às mesas de jogo de cartas, muitas vezes misturam-se com os homens. 
Porém, normalmente, as mulheres que jogam baralho o fazem nas residências, entre familiares ou entre amigos. Em menor quantidade, as mulheres também jogam bocha e participam de campeonatos locais e municipais.

Vale destacar a Mora, um jogo muito praticado em décadas atrás e, atualmente, em fase de extinção. Trata-se de um jogo de agilidade mental, cujo objetivo é acertar a soma dos dedos entre os jogadores, configurando um cenário de muita euforia, ruídos e expressões no idioma italiano. Conforme relatos e observações em Bento Gonçalves, o jogo atrai muitos observadores e deles o riso e a admiração. Em ambos os municípios pesquisados, a Mora aparece como demonstração e espetáculo, para que as novas gerações ou o público presente em festividades possam conhecer. Somente algumas pessoas, com idade acima de 50 anos, conservam a habilidade o jogo. Romoaldo Dalmolin destaca que "[...] os números eram ditos todos em italiano [...] a vizinhança ficava em volta da mesa vendo aquela gritaria, muitos chegavam perder a voz de tanto gritar". (Entrevista - Romoaldo Dalmolin, 77 anos, Bento Gonçalves, 27-052010).

A esfera do jogo, a partir da presença de uma aura mais alegre, conjuga certa liberação das leis e das normas da conduta ordinária para uma postura mais permissiva - mas subjazem as desigualdades, as diferenças e as contradições, visíveis, por exemplo, na associação do jogo ao universo masculino, nas expressões de negação dirigida à presença de pessoas de classe e origem social distinta, quer para dialogar quer para compartilhar o jogo. Mesmo que mulheres tenham conquistado uma parte desse espaço, antes hegemonicamente masculino, ainda assim, é como se elas ocupassem por empréstimo um lugar à mesa de jogos.

\section{Considerações}

Pode-se dizer que no cotidiano dos municípios e dos grupos sociais investigados apresenta-se uma diversidade de jogos tradicionais. Há, também, apropriação de jogos de um grupo social 
por outro (a exemplo do Bolão pelos descendentes italianos), mas o mais expressivo é a preservação do legado de ludicidade dos jogos do seu grupo social.

Percebemos, a partir da lógica interna e externa dos jogos, que tais manifestações tradicionais interagem para além do contexto familiar, ou seja, os jogadores como membros de grupos sociais assumem papéis que alimentam a transmissão desses elementos culturais. Lembrando Bourdieu (2004), o habitus é constituído por um conjunto de disposições para a ação, é a história incorporada, inscrita no cérebro e no corpo, nos gestos e nos modos de falar, enfim, em tudo o que somos. E ao afirmar que somos esse conjunto de disposições, concluímos que as experiências que vivenciamos se somam a elas e se nos incorporam, pois é essa história incorporada que funciona como princípio gerador do que fazemos ou das respostas que damos à realidade e persiste na realidade social.

A preocupação com a manutenção das Sociedades como centros de sociabilidade e vivência lúdica é constante; mas, dados os mecanismos avassaladores que marcam o público em favor do privado e do lucrativo, e que empobrecem os pequenos municípios, percebe-se que os recurso e estratégias institucionais ainda transformam a cultura produzida pelo povo em mercadoria consumível ou, discrimina-a, como sendo elemento do passado.

Entretanto, para mudança dessa visão distorcida da realidade cultural, há necessidade de uma maior difusão entre os jovens. Schuch (2008) constatou que as Sociedades estão sofrendo um processo de envelhecimento, pois são poucos os jovens que participam delas. Também não existe uma sucessão de cargos destas entidades, como diretores e secretários, permanecendo as mesmas pessoas na gestão. Na esteira de Burgos et. al. (2006), há necessidade de uma política de difusão dos jogos tradicionais, de desenvolvimento das suas práticas e do conhecimento dos sentidos que reverberam no cotidiano das comunidades.

Muitas Sociedades que fizeram parte do universo social e lúdico dos grupos estudados não existem mais, outras se tornaram privadas, e outras ainda se mantêm com mensalidades, ações promocionais e 
doações. Também, sofrendo a influência da atual conjuntura, alguns jogos tradicionais estão somente na memória, outros em processo de extinção, outros em processo de revitalização e outros, ainda, em processo de esportivização.

Os jogos são, de qualquer modo, o espelho da sociedade que coloca em cena uma imagem viva das mentalidades da sua comunidade, os jogos fazem viver nos corpos de seus praticantes certos traços marcantes de sua cultura. É assim que os jogos tradicionais do Rio Grande do Sul podem fazer reviver o patrimônio de um passado, em processo acelerado de mudanças, mas cuja população atual, à revelia das mutações sociais, representa seu indiscutível prolongamento.

O coração do estudo está bem aí: o jogo faz parte da cultura; ele é um dos elementos do patrimônio imaterial de um povo. Esta propriedade foi classicamente o ponto cego das representações sociais e foi constantemente recusada pela inteligentsia que alegava desprezar as manifestações do corpo. Somente em 2010 foi que a Organização das Nações Unidas para a Educação, a Ciência e a Cultura (UNESCO), por exemplo, mudou de atitude e decidiu inscrever na lista das práticas do patrimônio cultural os jogos tradicionais, tais como as pirâmides humanas da Catalunha, a luta tradicional da Turquia e certos jogos da Mongólia. (LAVEGA BURGUÉS, et. al., 2011)

Em suma, o Rio Grande do Sul é um cruzamento de civilizações que deu origem a confrontos ligados a inúmeras ondas de colonização, subterrâneas ou diretas. No plano dos jogos, seguiu-se uma multiplicidade de práticas lúdicas importadas pelos grupos sociais. Esta região do Brasil ilustra no plano local um fenômeno de nível mundial: uma ludodiversidade proliferante que propõe aos jogadores - descendentes de italianos e de alemães - algumas práticas cujas respectivas lógicas internas são bastante diversas e frequentemente originais.

É plausível pensar que os jogos dos grupos sociais estudados foram influenciados por uma prática oriunda dos países de origem, e 
que às vezes até mesmo não passasse de uma réplica. No entanto, num ângulo cultural, o que conta é a forma ressignificadas em território brasileiro. Nesse caso, torna-se outro jogo, próprio da cultura de adoção que finalmente o transformou e o recriou de acordo com as significações singulares. O jogo é portador de um imaginário relacional, poético, e mesmo político, cuja sobrevivência depende da história da população de ancoragem. 


\begin{abstract}
Juegos tradicionales en el Estado de Rio Grande do Sul: manifestación vibrante y silenciada Resumen:Este artículo resulta de investigación descriptiva con el objetivo de situar los juegos tradicionales en el contexto sociocultural e histórico de RS, que se celebró en las ciudades con importantes vestigios de las culturas alemana e italiana. Para recoger los datos, usamos formas y guiones de encuestas semi-estructuradas. Podemos decir que hay tanto una diversidad de juegos todavía vivenciados, y son las asociaciones y los bares la zona central de esta experiencia, cuánto juegos se han extinguido o en peligro de extinción, presentados hoy cómo espectáculo. Los juegos tradicionales en RS hacen revivir la herencia del pasado en un acelerado proceso de cambio, pero que para la generación actual, incluso con el cambio social, es cierto que representan una extensión histórica indiscutible.
\end{abstract}

Palabras clave: Cultura Alemana. Cultura Italiana Juegos tradicionales. Patrimonio cultural.

Traditional games in the State of Rio Grande do Sul: vibrant and muted expression

Abstract: This article is descriptive research with the objective of bringing the traditional games in the sociocultural and historical context of RS, held in cities with significant traces of German and Italian cultures. For the collection of information, we used forms and semi-structured interviews. We can say that there is both a diversity of games being experienced, and local associations and the central bars of this experience, the game is extinct or endangered, today presented as a spectacle. Traditional games in $\mathrm{RS}$ revive the heritage of the past in an accelerated process of change, but for the present generation, even with social change, it is true that represent an indisputable historical range.

Keywords: German Culture. Italian Culture. Traditional Games. Cultural heritage. 


\section{REFERÊNCIAS}

BENEVENUTO, Álvaro Fraga Moreira; SEIBT, Renato Urbano; SEIBT, Elisabeth. Christina. Sociedade Cultural e Recreativa Tiro ao Alvo: 110 anos de cultura. Nova Petrópolis (RS): Editora Amstad, 2006.

BONI, Luis Alberto de, COSTA, Rovílio. Os Italianos no Rio Grande do Sul. Porto Alegre: EST Edições, 1982.

BOSI, Alfredo. Cultura como tradição. In: BORNHEIM, Gerd et al. Cultura Brasileira: tradição, contradição. Rio de Janeiro: Zahar, 1987. p.31-58

BOSI, Alfredo. Dialética da Colonização. São Paulo: Companhia da Letras, 1992.

BOURDIEU, Pierre. A economia das trocas simbólicas. 5.ed. 2.reimp. Tradução de Sergio Miceli. São Paulo: Perspectiva, 2004.

BRASIL. INSTITUTO BRASILEIRO DE GEOGRAFIAE ESTATÍSTICA(IBGE). Disponível em: : http://www.censo2010.ibge.gov.br/. Acesso em: 10 set. 2011.

LAVEGA BURGUÉS, Pere. Juegos y deportes populares tradicionales. Barcelona: INDE Publicaciones, 2000.

LAVEGA BURGUÉS, Pere. et al. Os Jogos Tradicionais no mundo: associações e possibilidades. Licere, Belo Horizonte, v.14, n. 2, p.01-19, 2011.

BURGOS, Miria Suzana. et al. Jogos tradicionais e legados históricos dos descendentes alemães em Santa Cruz do Sul e Sinimbu (RS). In: MAZO, Janice Zarpellon; REPPOLD FILHO, Alberto Reinaldo (orgs.). Atlas do esporte no Rio Grande do Sul. Porto Alegre: CREF2/RS, 2005. p. 13-14

CERVO, Amado Luiz; BERVIAN, Pedro Alcino. Metodologia da Pesquisa Científica: para uso de estudantes universitários. São Paulo: McGraw-Hill do Brasil, 1983.

COSTA, Rovílio. Imigração Italiana no Rio Grande do Sul: vida, costumes e tradições. Porto Alegre: Escola Superior de Teologia e Espiritualidade Franciscana, 1986.

GIRON, Loraine Solmp. A imigração italiana no RS: fatores determinantes. In: DACANAL, José H. (org.) Rio Grande do Sul: Imigração \& Colonização. Porto Alegre: Mercado Aberto, 1992. p. 47-66.

IANNI, Octávio. Aspectos políticos e econômicos da imigração italiana. In: BONI, Luis Alberto de. Imigração Italiana: estudo. Porto Alegre: Escola Superior de Teologia São Lourenço de Brindes: Universidade de Caxias do Sul, 1979. p.11-28.

MATTELART, Armand. Utopía y realidades del vínculo global. Para una crítica del tecnoglobalismo. Revista Diálogos de la comunicación, Lima, n. 50, p 9-25.1997. 
PARLEBAS, Pierre. Juegos, Deporte y Sociedad: Léxico de Praxiología Motriz. Barcelona: Paidotribo, 2001.

PAZ, Ivoni Nor. Nova Petrópolis: da submissão à rebeldia (1858-1937). Caxias do Sul: UCS, 1998.

RICHARDSON, Roberto Jarry (Org.). Pesquisa Social: métodos e técnicas. 3.ed. 11. reimp. São Paulo: Atlas, 2010.

RIO GRANDE DO SUL. Federação Gaúcha de Bocha. Disponível em: < http:// www.portaldabocha.com.br/frgb/. > Acessado em: 24 out. 2011.

ROCKENBACH, Sílvio Aloysio; FLORES, Hilda Agnes Hübner. Imigração alemã: 180 anos - história e cultura. Porto Alegre: CORAG, 2004.

SANTOS, Milton. A natureza do espaço: Técnica e Tempo. Razão e Emoção. São Paulo: Edusp, 2004.

SCHMTIZ, Pe. Arsênio José. Uma nova imagem para Nova Petrópolis: estudo sobre a imigração e a aculturação. São Leopoldo: Publicação do autor, 1975.

SCHUCH, Heitor José. As sociedades alemãs: a cultura através dos tempos. Porto Alegre: Corag, 2008.

Pesquisa financiada pelo Ministério do Esporte/ Centro de Desenvolvimento do Esporte e Recreativo e de Lazer (ME/ REDE CEDES) e pelo Fundo de Incentivo à Pesquisa (FIPE) da Universidade Federal de Santa Maria (UFSM).

Endereço para correspondência:

Elizara Carolina Marin

Universidade Federal de Santa Maria

Centro de Educação Física e Desportos

Avenida Roraima №1000

Bairro Camobi

Santa Maria, RS, Brasil

Recebido em: 20.03.2012

Aprovado em: 27.06 .2012 
